firefighters. The aim was to evaluate the cancer incidence in Swedish firefighters.

Methods This cohort study is based on the Swedish part of the Nordic Occupational Cancer (NOCCA) project, including 6 million people who participated in one or more population censuses in 1960, 1970, 1980 and 1990. Cancer diagnoses 1961-2009 were obtained from the Swedish Cancer Registry. We identified 8136 male firefighters. Female firefighters were excluded because there were too few. SIRs were calculated with the cancer incidence rates for the entire national population used as reference rates.

Result There was no excess risk for all cancer sites combined ( $\mathrm{SIR}=1.01,95 \% \mathrm{CI}: 0.96$ to 1.06$)$. A statistically significant excess was found only for non-melanoma skin cancer ( $\mathrm{SIR}=1.48,95 \% \mathrm{CI}: 1.20$ to 1.80 ), although the risk did not increase with duration of employment. There was a small, but statistically significant excess of prostate cancer among firefighters who had worked 30 years or more.

Discussion The risk of prostate cancer was increased among longterm exposed firefighters, and a possible excess of non-melanoma skin cancer was found. An increased risk of prostate cancer has been reported in some earlier studies of firefighters, but excesses of others cancers earlier reported in association with firefighting were not confirmed. Our results do not support an overall excess risk of cancer among Swedish firefighters.

\section{MYOCARDIAL INFARCTION AND RETURN TO WORK}

${ }^{1} \mathrm{E}$ Gadzicka*, 'J Siedlecka, ${ }^{1} \mathrm{~T}$ Makowiec- Dąbrowska, ${ }^{1} \mathrm{P}$ Viebig, ${ }^{1} \mathrm{~A}$ Szyjkowska, ${ }^{2} \mathrm{~K}$ Wranicz, ${ }^{3} \mathrm{E}$ Trzos, ${ }^{3} \mathrm{M}$ Kurpesa, ${ }^{4} \mathrm{~W}$ Szymczak, ${ }^{1} \mathrm{~A}$ Bortkiewicz. ${ }^{1}$ Nofer Institute of Occupational Medicine, Department of Work Physiology and Ergonomics, Lodz, Poland; ${ }^{2}$ Medical University of Lodz, Department of Electrocardiology Poland; ${ }^{3}$ Medical University of Lodz, Department of Cardiology, Poland; ${ }^{4}$ University of Lodz, Department of Psychological Research Methodology and Statistics, Poland

\subsection{6/oemed-2018-ICOHabstracts. 1078}

Introduction After myocardial infarction (MI) only 50\% to $60 \%$ of people still work and the time to stay out of work is in Poland often 9 months. The aim of the project was to elicit factors that have an impact on the return to work after the first myocardial infarction.

Methods A questionnaire survey was performed among all patients occupationally active till the time of the MI. The questionnaire covered recent data on work, working environment, health status, lifestyle. 306 people received the questionnaire. The analysis included 150 surveys.

Results As much as $76.7 \%$ (115) people returned to work. The average age of workers prior to infarction was 52.6 \pm 7.1 years, and was significantly lower than that of people who did not return $(55.3 \pm 6.8)$. The subjects returned to work after an average of 6.5 months (range $0.5-48$ ). The group of people who returned/did not return to work did not differ in respect to education, place of residence, classical risk factors, type of MI, ejection fraction and undertaken rehabilitation. Subjects who returned to work significantly more likely used to undertake physical activity. People who did not return to work significantly more often rated their health as 'worse than before the MI' $(\mathrm{p}=0.026)$ complained the chest pain $(71.4 \%$ vs $38.6 \%, p=0.026)$, suffered from neurosis $(25,7 \%$ vs $10.4 \%, \mathrm{p}=0.047)$ and were anxious about re-infarction (71.4\% vs $49.6 \%, p=0.023)$. As many as $20.9 \%$ of subjects claimed that the work was too heavy, while for $49.6 \%$ the job was too stressful.
Discussion The results indicate that age, subjective health status and the presence of pain in the chest, neurosis and anxiety play an important role in the return to work after MI. For people who restarted working, work heaviness and stress occurring at work were the major problems.

\section{DIETARY HABITS IN OCCUPATIONALLY ACTIVE MEN WITH FIRST MYOCARDIAL INFARCTION}

${ }^{1}$ A Bortkiewicz*, ${ }^{1} E$ Gadzicka, ${ }^{1} \mathrm{~J}$ Siedlecka, ${ }^{1} \mathrm{~A}$ Szyjkowska, ${ }^{1} \mathrm{P}$ Viebig, ${ }^{2} \mathrm{JK}$ Wranicz, ${ }^{3} \mathrm{M}$ Kurpesa, ${ }^{3} \mathrm{E}$ Trzos, ${ }^{1} \mathrm{~T}$ Makowiec-Dąbrowska. ${ }^{1}$ Department of Work Physiology and Ergonomics Nofer Institute of Occupational Medicine Lodz, Poland; ${ }^{2}$ Department of Electrocardiology, Medical University of Lodz, Poland; ${ }^{3}$ Department of Cardiology Medical University of Lodz, Poland

\subsection{6/oemed-2018-ICOHabstracts. 1079}

Introduction Only a few studies have been undertaken to analyse the dietary habits of people with cardiovascular diseases. The aim of this study was to evaluate the dietary behaviours of working people after the first acute cardiovascular incident. Methods In the study Functional Activity Questionnaire (FAQ) was used. The study was performed in two groups: the first group were all men hospitalised during one year in two clinics of cardiology, professionally active until the first myocardial infarction (MI). It comprised 243 men, aged 26-70 years. The reference group consisted of 403 men, blue- and white-collar workers aged 35-65 years. Frequency of consumption of each product among patients with acute myocardial infarction and in the reference group was calculated using basic methods of descriptive statistics. Multivariate logistic regression model was used to determine the risk factors for myocardial infarction. All statistical analyses were performed using the STATISTICA version 8 MR 3 c software.

Results Body mass index of MI patients was significantly higher $(p=0.006)$. The frequency of consumption of particular products in MI group and in the reference group differed significantly for 11 of 21 products. Patients with MI significantly less frequently reported daily consumption of fruits, raw vegetables, cheese, vegetable fats and fish. In this group consumption of salty $(p=0.0226)$ or fatty $(p<0.0001)$ foods were significantly higher.

Discussion It has been shown that after adjusting for age, education and type of work, the daily consumption of fish, salads and cooked vegetables, fruits and vegetable oils significantly reduced the risk of myocardial infarction. Increased MI risk was associated with obesity and preference for fatty foods. We found, that the diet significantly modified risk of MI in examined workers. This indicates that an important part of prevention activities among working people should be an education about proper dietary habits.

\section{A HEALTH-BASED RISK ASSESSMENT FRAMEWORK IN THE WORKPLACE TO INTEGRATE THE MANAGEMENT OF HEALTH AND SAFETY RISKS: A REVIEW}

Jeff Yi-Fu Hwang*, Sin Eng Chia, Judy Sng. Saw Swee Hock School of Public Health, National University of Singapore, Singapore

\subsection{6/oemed-2018-ICOHabstracts. 1080}

Introduction Despite significant global improvement in occupational health and safety over the past few decades, workplace deaths and injuries are still occurring. At the same time, many 
countries are experiencing an increasing prevalence of chronic diseases due to ageing population and lifestyle factors. Our paper aims to review the association between chronic diseases and risk of workplace injuries, and propose a health-based risk assessment framework which would incorporate employees' health factors into the risk assessment process which employers are familiar with.

Methods We first reviewed the evidence for the association between chronic diseases and risk of injuries in the workplace through literature review. Subsequently, we proposed a healthbased risk assessment framework that incorporates employees' health factors, giving examples on how this can be done, and at the same time highlight some of the challenges.

Results Many recent studies found that increased body mass index was associated with higher risk of injuries, while older workers were at risk of more severe injuries. Diabetes mellitus was also associated with workplace injuries in some studies. There were fewer studies looking at other chronic diseases such as hypertension. Our proposed health-based risk assessment framework incorporates employees' health into the risk assessment process outlined in the current Code of Practice for Risk Assessment, in a similar way as that for occupational health and safety hazards.

Discussion A health-based risk assessment framework can improve the integration of health and safety and minimise the need to have different methods of managing health and safety.

\section{ANALYSIS OF UNSTABLE CHROMOSOMAL ABERRATIONS FREQUENCY, MICRONUCLEI TEST, HAEMATOLOGICAL PARAMETERS AND RECEIVED DOSES BY PROFESSIONALS EXPOSED TO IONISING RADIATION}

\begin{abstract}
1,2Jelena Djokovic*, ${ }^{3}$ Jadranko Simic, ${ }^{4}$ Vojislav Antic, ${ }^{1,5}$ Milan Gajic, ${ }^{1,2}$ Aleksandar Milovanovic, ${ }^{1,2}$ Petar Bulat. 'School of Medicine, University of Belgrade, Belgrade, Serbia; 'Serbian Institute of Occupational Health 'Dr Dragomir Karajovic', Belgrade, Serbia; ${ }^{3}$ South East Europe Consultants - SEEC, Belgrade, Serbia; ${ }^{4}$ Centre for Nuclear Medicine, Clinical Centre of Serbia, Belgrade, Serbia; ${ }^{5}$ Institute of Medical Statistics and Informatics, Belgrade, Serbia
\end{abstract}

\subsection{6/oemed-2018-ICOHabstracts. 1081}

Introduction Ionising radiation is often used in medicine for diagnostic and therapeutic purposes. Radiation workers exposed to ionising radiation have to follow all the safety measures and precautions at their work. The purpose of this article was to analyse the impact of low-dose ionising radiation to medicine professionals exposed to ionising radiation of the Clinical Centre of Serbia.

Methods Data from the last medical check-ups, obtained from the medical records of 148 employees from Clinical centre of Serbia, were analysed. They were divided into tree groupsempoyees in nuclear medicine, in interventional radiology and general radiology. A typical check-up, haematological parameters analysis, as well as special cytogenetical analyses, such as unstable chromosomal aberrations and micronucleus test, were carried out. The received cumulative 5 year dose was measured by personal inactive thermoluminescent dosimeters calibrated into personal doses equivalent Hp (10).

Results By comparing the results of the frequency of unstable chromosomal aberrations in the last periodical check-up of the employees in all the three groups we have found that the nuclear medicine employees had a significantly higher frequency of unstable chromosomal aberrations $\left(x^{2}=6.634\right.$; $\mathrm{p}<0.05)$. Employees in nuclear medicine had significantly lower levels of red blood cells as compared to employees in general and interventional radiology. Statistically higher platelet count was ascertained with the employees in general radiology (ANOVA, p <0.01). Nuclear medicine employees have received statistically higher cumulative dose than the employees in interventional radiology and general radiology $\left(x^{2}=23.465\right.$; $\mathrm{p}<0.01)$. There is also no statistically significant difference in the outcome of the micronucleus test between groups of employees $\left(x^{2}=1.245 ; \mathrm{p}>0.05\right)$.

Discussion Out of the three groups of employees tested, nuclear medicine employees have increased health risks than employees in interventional radiology and general radiology. There is a need to monitor their health condition by periodical check-ups for prevention from occupational diseases.

\section{THUNDERSTORM ASTHMA IN THE MEDITERRANEAN AREA: SEASONAL WEATHER AND EFFECT ON HEALTH FOR OUTDOOR WORKERS}

${ }^{1} \mathrm{G}$ D'Amato, ${ }^{2}$ Annesi-Maesano, ${ }^{3} \mathrm{C}$ Grandi, ${ }^{4,5} \mathrm{~L}$ Cecchi, ${ }^{3} \mathrm{MC} \mathrm{D}^{\prime}$ Ovidio*.${ }^{1}$ Division of Respiratory and Allergic Diseases, Department of Chest Diseases, High Speciality A. Cardarelli Hospital, Naples, Italy; ${ }^{2}$ Epidemiology of Allergic and Respiratory Diseases Department (EPAR), Pierre Louis Institute of Epidemiology and Public Health (IPLESP UMRS1136), UPMC Univ Paris 06, INSERM, Saint-Antoine Medical School, Sorbonne Universités, Paris, France; ${ }^{3}$ National Workers' Compensation Authority (INAIL), Department of Occupational and Environmental Medicine, Epidemiology and Hygiene, Monte Porzio Catone (RM), Italy; ${ }^{4}$ UOSD Allergy and Clinical Immunology, USL4 Prato, Italy; 5 Interdepartmental Centre of Bioclimatology, University of Florence, Florence, Italy

\subsection{6/oemed-2018-ICOHabstracts. 1082}

Introduction An increasing body of evidence shows the occurrence of asthma epidemics, sometimes also severe, during thunderstorms in the pollen season, in various geographical zones. Thunderstorms have been linked to asthma epidemics and there are descriptions of asthma outbreaks associated with thunderstorms in several cities, prevalently Australia (Melbourne) and Europe (in UK Birmingham and London, and in Italy in Naples). Considering this background it is important to promote the dissemination of these evidence also in occupational setting.

Methods Analysis of literature was performed on asthma, thunderstorm, occupational health. Description of these events in the Mediterranean area was also investigated.

Results Asthma outbreaks associated with thunderstorms occurred in several cities as London (24/25 June 1994) and Melbourne (21 November 2016). In the first outbreak 640 patients with asthma or other airway diseases attended London hospitals (nearly 10 times the usual number); in Melbourne, hospitals were swamped with emergency patients affected by severe asthma attacks (more than 8500 patients across Monday night and Tuesday and 8 died). The frequency of thunderstorms had recently increased in some geographical areas, particularly in temperate and subtropical climates. Research has shown that thunderstorms are expected to become more severe as the climate changes.

Conclusion Thunderstorms have been linked to asthma epidemics, especially during the pollen seasons. There is evidence that hat under wet conditions or during thunderstorms, pollen grains, release into the atmosphere their content that can reach lower airways inducing asthma reactions.

All individuals affected by pollen allergy should be alerted to the danger of being outdoors during a thunderstorm in the 